\title{
Radical Functionalization of Thioglycosides in Aqueous Medium
}

\author{
Sarbjeet Kaur, Dominic Luciano, Gaoyuan Zhao, and Ting Wang* \\ Department of Chemistry, University at Albany, State University of New York, \\ 1400 Washington Avenue, Albany, New York 12222, United States \\ twang3@albany.edu
}

\begin{abstract}
A visible-light-mediated thiol-ene reaction is successfully operated in aqueous medium. Organic photoredox catalyst (9-mesityl-10-methylacridinum tetrafluoroborate) is used to initiate the radical process to generate thiyl radicals upon light irradiation. Two reaction pathways are discovered in different aqueous buffer system. Thiol-ene adduct is preferred in acidity reaction medium; while disulfide formation is found to be favored in basic reaction medium. Moreover, a visible-light-mediated modified Danishefsky-Wan desulfurization is used to convert thioglycoside to highly substituted tetrahydropyran ring.
\end{abstract}

Sulfur radicals have played important roles in many biological systems. For example, the cysteine residue in many proteins, such as thioredoxin, could serve as the sulfur radical precursor., ${ }^{1,2}$ Those resulting sulfur radicals heavily involved in a variety of enzymatic processes. ${ }^{1}$ Inspired by nature, the sulfur radicals have also attracted significant attention in synthetic community.3,4 Sulfur radicals are traditionally formed from thiols or disulfides by using radical initiators or UV irradiation. The resulting sulfur radicals could react with a broad range of radical acceptors, such as alkenes (thiol-ene reaction), and alkynes (thiol-yne reaction). ${ }^{5}$ Particularly, the thiol-ene reaction is a powerful method that has been widely employed in areas of bioconjugate chemistry, polymer science and pharmaceutical chemistry. ${ }^{3,4}$ Recently, visible-light photoredox catalysis has been developed into a useful tool in organic synthesis. ${ }^{6}$ The use of such strategy in thiol-ene reaction ${ }^{7}$ excluded the needs of stoichiometric radical initiator or expensive specialized UV photochemical equipment. In 2013, Yoon reported the first visible-light photoredox catalyzed thiol-ene reaction using $\mathrm{Ru}(\mathrm{bpz}) 3^{2+}$ as photocatalyst. ${ }^{8}$ In the following years, several groups, including our group, have reported visible-light-mediated thiol-ene reactions by using different photocatalysts.9,10 Such visible light photocatalytic thiol-ene strategy provided a much milder reaction conditions, which could be potentially useful in a variety of synthetic applications.

In addition the development of sulfur radical reactions in organic solvents, it has also been shown that the sulfur radicals could be compatible in aqueous medium. Since the alkyl RS-H bond (BDE $=\sim 87 \mathrm{kcal} / \mathrm{mol}$ ) is weaker that the $\mathrm{HO}-\mathrm{H}$ bond $\left(\mathrm{BDE}=\sim 119.3 \mathrm{kcal} / \mathrm{mol}\right.$ ), the sulfur radicals would not be quenched in $\mathrm{H}_{2} \mathrm{O}$. Therefore, operating sulfur radical reactions in aqueous medium would be a 
promising area. Such success would particularyly expand the scope of sulfur radical reaction in glycopeptides' synthesis because of the poor solubility of protected peptides in organic solvents and difficulty of purification of protected peptides. In 1998, Oshima and co-workers reported a radical addition of benzenethiol (1) to Nacetyldiallylamine (2) in water, affording $\mathrm{N}$-acetylpyrrolidine derivative $\mathbf{3}$ in excellent yield (Scheme 1a). ${ }^{11}$ In addition to application in the small molecules synthesis, the Danishefsky-Wan desulfurization significantly broadens the synthetic merits of the native chemical ligation (NCL) in peptide/protein synthesis (Scheme 1b). ${ }^{12}$ By using water-soluble radical initiator (VA-044), the cysteine in a polypeptide (4) could be converted to corresponding alanine (5) through a radical mechanism. With such development, the NCL strategy would no longer limited on Cysteine site. The metal-free process also make it practically useful in polypeptides and glycopeptides' synthesis. More recently, Davis and co-workers reported a radical thiol-ene reaction was applied in a convergent synthesis of S-linked glycoconjuates (Scheme 1c). ${ }^{13}$

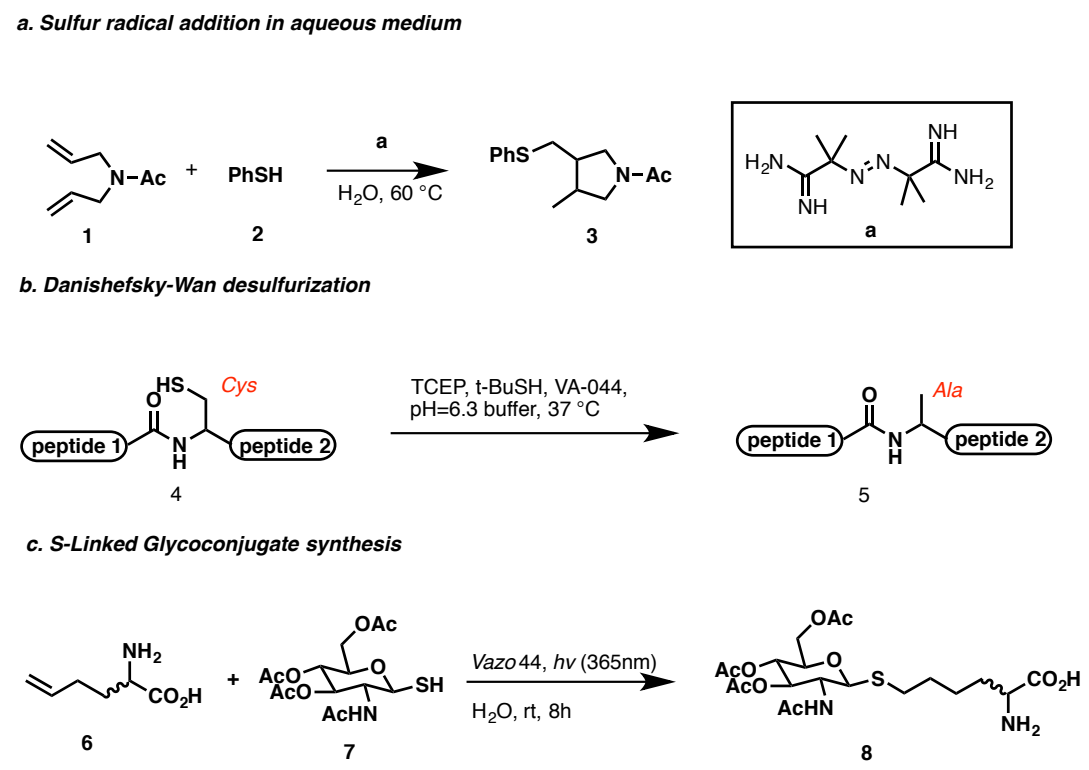

Scheme 1. Examples of sulfur radical reaction in aqueous medium.

S-linked glycoconjugates have become useful analogs of glycopeptides and glycoproteins because of their improved chemical stability and enzymatic resistance. ${ }^{14}$ Inspired by Davis' thiyl glycosylation work, ${ }^{13}$ we were also interested in applying our metal-free visible-light-mediated thiol-ene reaction in aqueous medium. Our study was commenced by testing the reaction between glycosyl thiol (9) and allyl alcohol (10) in water in presence of photocatalyst (9-mesityl-10methylacridinum tetrafluoroborate). Happily, thiol-ene adduct (11) could be obtained in good yield under blue light-emitting diode (LED) irradiation (72\%, Scheme 2a). The reaction performed even better in $\mathrm{CH}_{3} \mathrm{CN} / \mathrm{H}_{2} \mathrm{O}$ (1:1) mixture, probably due to the better solubility of the protected glycosy thiols in the solvent (85\%, Scheme $2 \mathrm{~b})$. Since majority of glycoconjugate reaction were performed in 
aqueous buffers, we next attempted the radical thiol-ene reaction in buffers with common $\mathrm{pH}$ value, $\mathrm{pH}=6$ and $\mathrm{pH}=8$ respectively (Scheme 2c, 2d). Surprisingly, beside the desired thiol-ene adduct 11, an unexpected disulfide byproduct 12 was isolated, $12 \%$ and $20 \%$ respectively (Scheme 2c, 2 d). The results also show that the byproduct formation was enhanced in more basic aqueous medium.

b
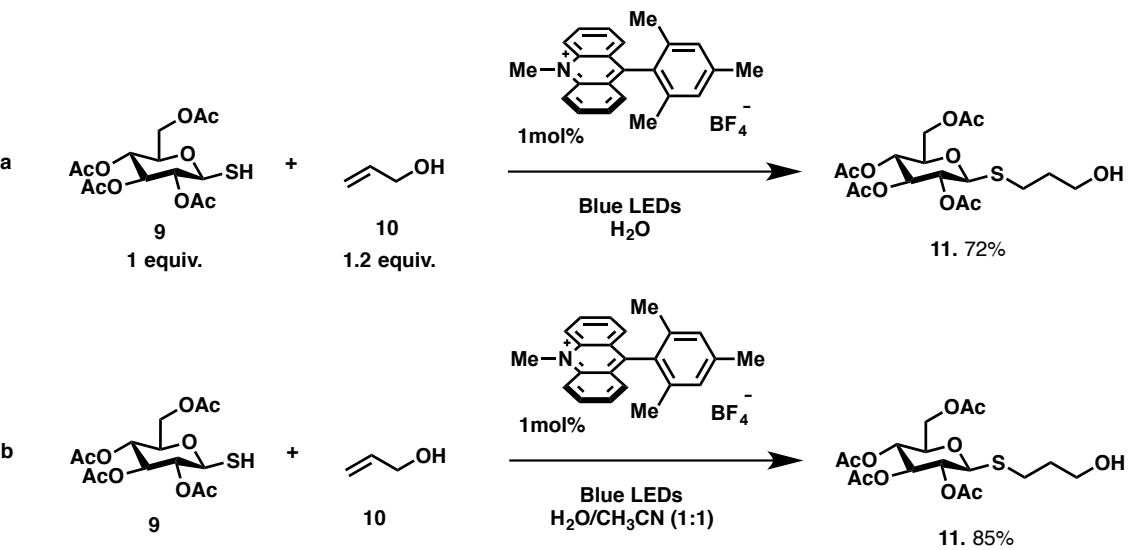

c
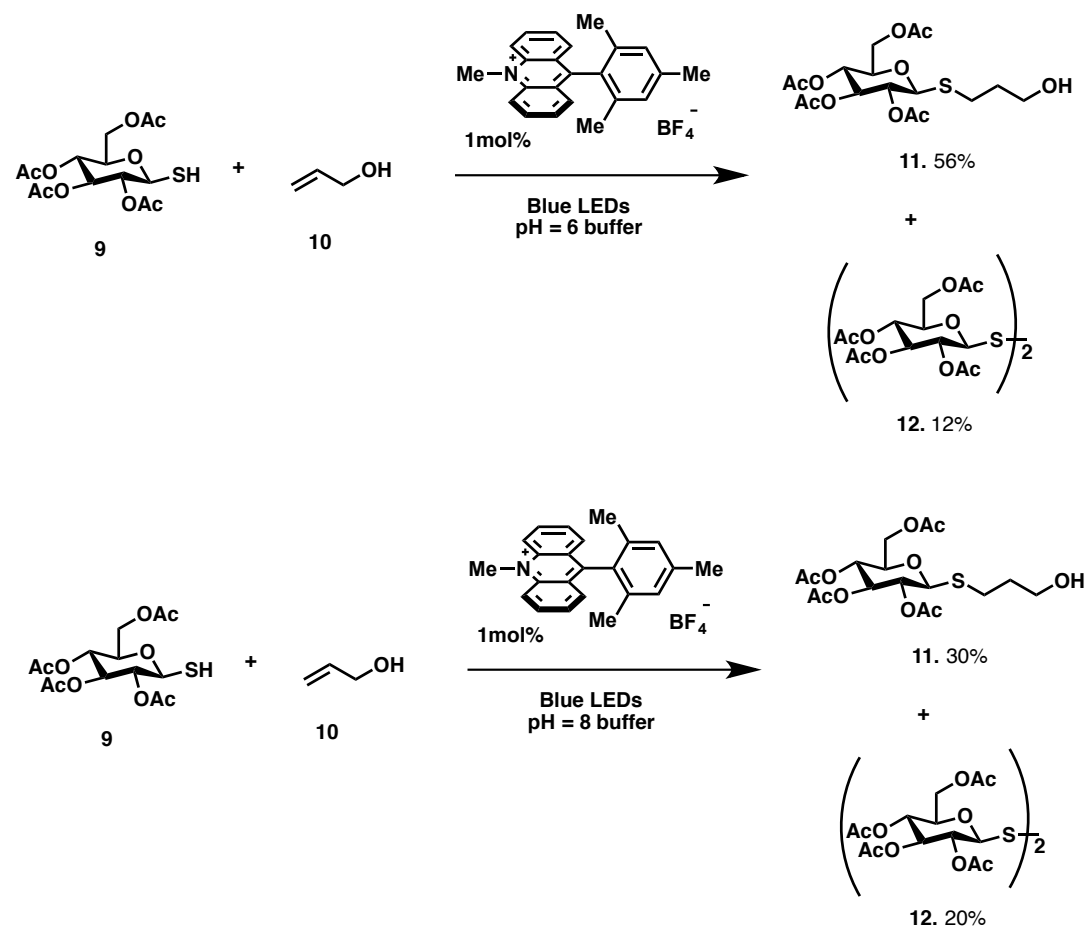

Scheme 2. Visible-light-mediated thiol-ene reaction in aqueous medium 
Intrigued by these results, we went back to organic solvent to check if base additive would affect thiol-ene reaction outcome. We have previously reported that the thiol-ene adduct $\mathbf{1 4}$ could be afforded in excellent yield between benzyl mercaptan (13, 1 equiv.) and allyl alcohol (10, 1.2 equiv.) (Scheme 3a).10 We then added triethylamine as additive in a separate reaction (Scheme 3b). Surprisingly, only disulfide product $\mathbf{1 5}$ was obtained under such condition with a yield of $70 \%$. Such base mediated photocatalytic disulfide formation is consistent with previous report by Noel. ${ }^{15}$ However, the competing reaction pathway between thiol-ene reaction and disulfide formation have drawn our interest.

a

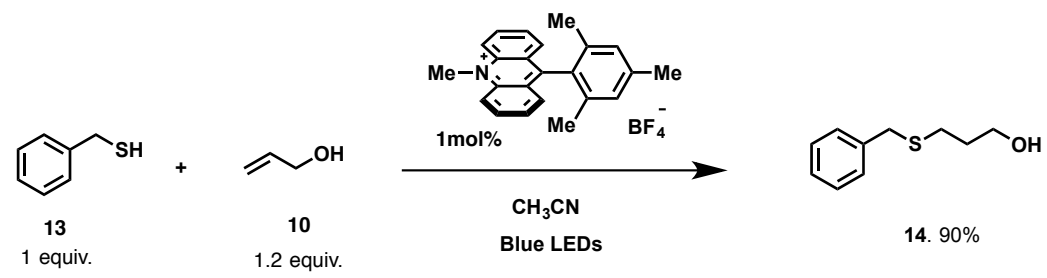

b
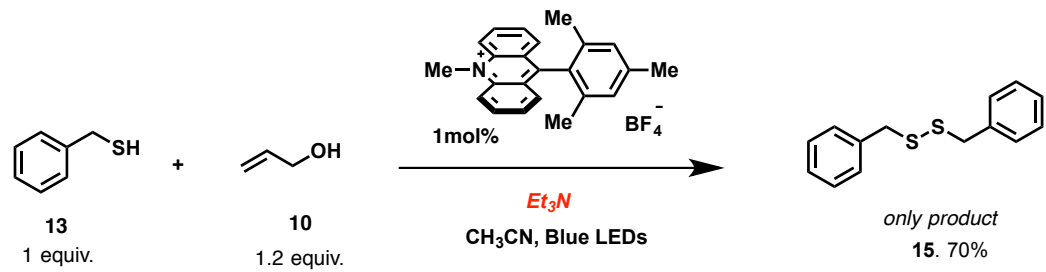

Scheme 3. Base promoted disulfide formation.

We next carefully screen the effect of the $\mathrm{pH}$ value of the aqueous medium. Davis has reported the some of the glycoconjugate formation favored more acidic medium ( $\mathrm{pH}=4$ in some cases). ${ }^{13}$ We then attempted the photocatalytic thiol-ene reaction in $\mathrm{pH}=4$ buffer (Table 1 , entry 3 ). Gladly, we observed the suppression of the disulfide formation ( $5 \%$ of $\mathbf{1 2}$, Table 1 , entry 3 ). In contrast, more disulfide byproduct was isolated in more basic medium ( $\mathrm{pH}=8$ buffer, $36 \%$ of 12, Table 1 , entry 4). This trend clearly suggested that increasing the acidity of the aqueous medium would favor the thiol-ene reaction, while dimerization would be preferred in more basic medium. Finally, we figured out the dimerization could be completely suppressed in $\mathrm{pH}=2.6$ buffer, providing thiol-ene product $\mathbf{1 1}$ as only product in $72 \%$ (Table 1, entry 5). Control reaction (Table 1, entry 6) has shown the light is necessary in this reaction, excluding the possibility of acid-promoted reaction in such acidity medium. 
Table 1. Visible-light-mediate thiol-ene reaction in buffers

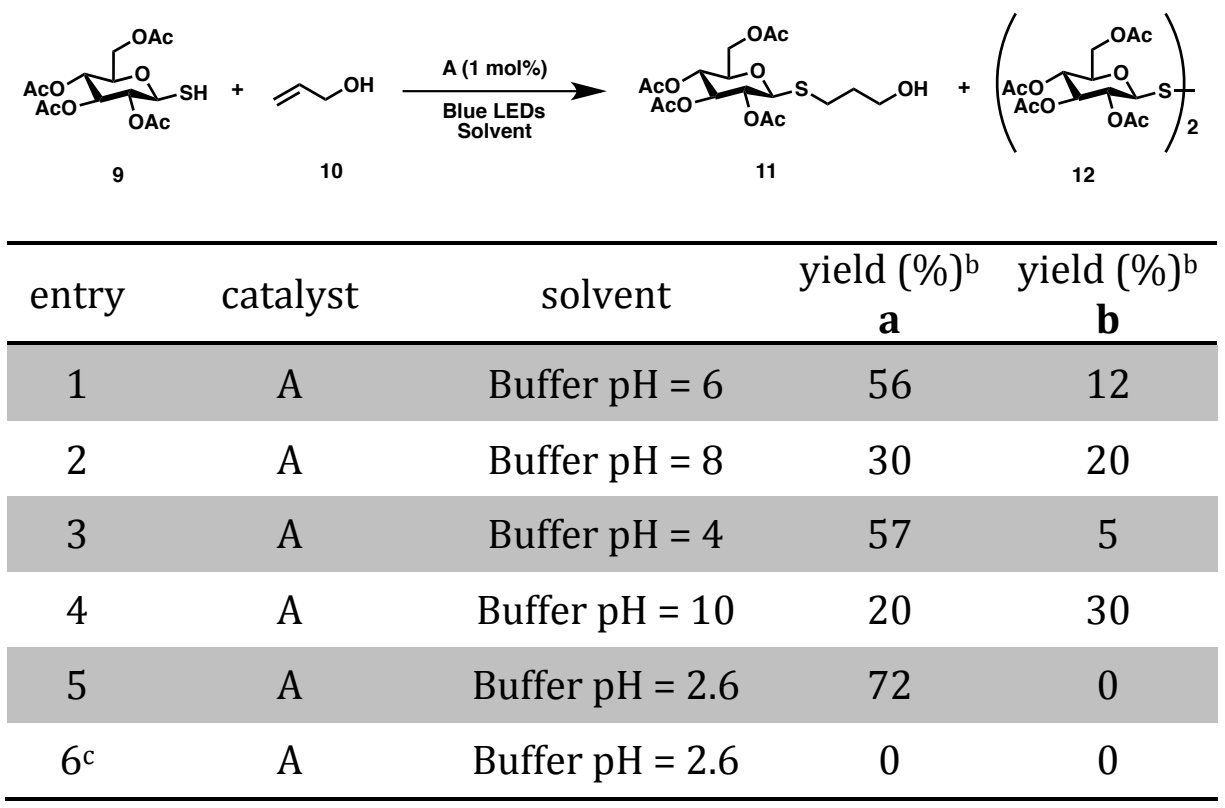

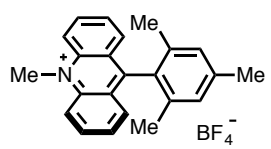

aReactions were conducted by irradiating $1(0.137 \mathrm{mmol}), 2(0.165 \mathrm{mmol})$, and the photocatalyst (1 mol\%) in solvent $(0.274 \mathrm{~mL})$ with two $12 \mathrm{~W}, 450 \mathrm{~nm}$ LED floodlamps for $6 \mathrm{~h}$. bIsolated yield 'Reaction was conducted in dark.

A proposed mechanism for the formation of thiol-ene product and disulfide byproduct is outlined in Scheme 4. Upon on photocatalytic single electron oxidation of thiol (16), key intermediate thiyl radical cation (17) would be formed along with one electron reduced acridinium 18.16,17 We proposed two pathway in this stage: 1) in acidic medium, thiyl radical would be released slowly, giving relative low concentration of thiyl radical. A thiol-ene reaction was favored in this pathway, coupling with the alkene with anti-Markovnikov selectivity; 2) on the other hand, thiyl radical would go through a fast releasing in basic medium. The relative high concentration of thiyl radical favors the dimerization, affording disulfide product. Oxidation of $\mathbf{1 8}$ by molecule of oxygen would regenerate photocatalyst A (Scheme 4). 


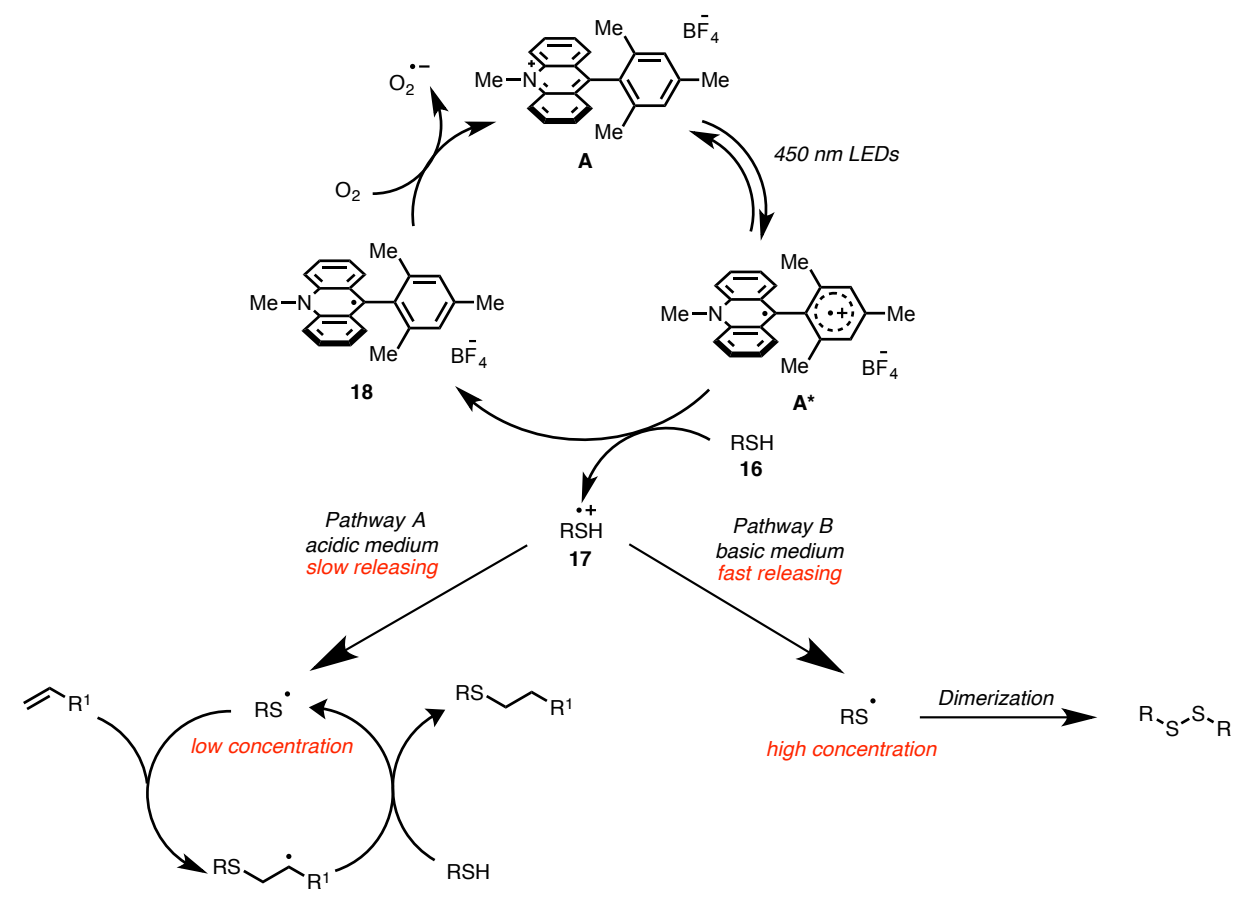

Scheme 4. Proposed mechanism

Encouraged by the success of visible-light mediated radical addition of thioglycosides to alkene, we next wonder if we would apply such photocatalytic method to mimic the Danishefsky-Wan desulfurization strategy, converting thioglycoside to a highly substituted tetrahedropyran ring. Instead of excess employment of radical initiator VA-044, we attempted to generate the thiyl radical by visible-light photoredox catalysis. We would happy to report our preliminary result on such transformation. In presence of photocatalyst A (8 mol \%), t-BuNC, and blue LEDs, the desulfurization product 19 was obtained in 56\% yield (Scheme 5). Although the reaction is currently operated in organic solvent $\left(\mathrm{CH}_{3} \mathrm{CN}\right)$, we envisioned that a photocatalytic desulfurization protocol could be compatible in aqueous medium. The investigation is on-going project in our laboratory.

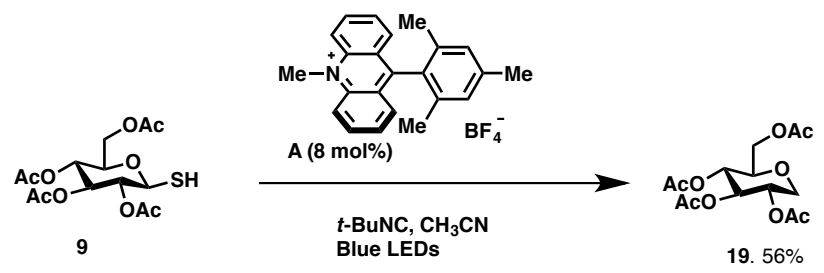

Scheme 5. Photocatalytic desulfurization.

In conclusion, we have developed a visible-light-mediated radical functionalization of thioglycoside in aqueous medium. Different reaction pathway, 
thiol-ene reaction or disulfide formation, could happen in different buffer system. Moreover, the photocatalytic method also demonstrated to be applicable in modified Danishefsky-Wan desulfurization. Application of the photocatalytic thiolene reaction between more sophisticated thioglycosides and peptides are ongoing in our laboratory.

\section{Author Information}

Corresponding Author

Email: twang3@albany.edu

\section{Notes}

The authors declare no competing financial interest.

\section{Acknowledgement}

We are grateful to the University at Albany, State University of New York, for financial support.

\section{Reference}

1. M. Kolberg, K. R. Strand, P. Graff, K. K. Andersson, Biochim. Biophys. Acta 2004, $1699,1$.

2. E. Torrents, P. Aloy, I. Gibert, F. Rodríguez-Trelles, J. Mol. Evol. 2002, 55, 138.

3. P. Chauhan, S. Mahajan, D. Enders, Chem. Rev. 2014, 114, 8807.

4. F. Dénès, M. Pichowicz, G. Povie, P. Renaud, Chem. Rev. 2014, 114, 2587.

5. For selective reviews on the applications of the thiol-ene/thiol-yne reaction, see: (a) C. E. Hoyle, T. Y. Lee, T. Roper, J. Polym. Sci. Part A: Polym. Chem., 2004, 42, 5301; (b) E. Sletten, C. R. Bertozzi, Angew. Chem. Int. Ed., 2009, 48, 6974; (c) C. E. Hoyle, C. N. Bowman, Angew. Chem., Int. Ed., 2010, 49, 1540; (d) A. Dondoni, A. Marra, Chem. Soc. Rev., 2012, 41, 573; (e) R. Hoogenboom, Angew. Chem., Int. Ed., 2010, 49, 3415; (f) A. Massi, D. Nanni, Org. Biomol. Chem., 2012, 10, 3791; (g) A. B. Lowe, C. E. Hoyle, C. N. Bowman, J. Mater. Chem., 2010, 20, 4745; (h) I. P. Beletskaya, V. P. Ananikov, Chem. Rev., 2011, 111, 1596; (i) R. Castarlenas, A. Di Giuseppe, J. J. Perez-Torrente, L. A. Oro, Angew. Chem., Int. Ed., 2013, 52, 211; (j) A. B. Lowe, Polymer, 2014, 55, 5517.

6. For selected reviews, see: (a) C. K. Prier, D. A. Rankic, D. W. C. MacMillan, Chem. Rev., 2013, 113, 5322; (b) M. N. Hopkinson, B. Sahoo, J. L. Li, F. Glorius, Chem. - Eur. J., 2014, 20, 3874; (c) M. D. Kärkäs, J. A. Porco Jr., C. R. J. Stephenson, Chem. Rev., 2016, 116, 9683; (d) J. Xuan, W.-J. Xiao, Angew. Chem., Int. Ed., 2012, 51, 6828; (e) T. P. Yoon, ACS Catal., 2013, 3, 895; (f) D. A. Nicewicz, T. M. Nguyen, ACS Catal., 2014, 4, 355; (g) S. Fukuzumi, K. Ohkubo, Org. Biomol. Chem., 2014, 12, 6059; (h) D. P. Hari, B. König, Chem. Commun., 2014, 50, 6688; (i) N. A. Romero, D. A. Nicewicz, Chem. Rev., 2016, 116, 10075; (j) J.-R. Chen, X.-Q. Hu, L.-Q. Lu, W.-J. Xiao, Chem. Soc. Rev., 2016, 45, 2044; (k) J.-R. Chen, X.-Q. Hu, L.-Q. Lu, W.-J. Xiao, Acc. Chem. Res., 2016, 49, 
1911; (l) J.-R. Chen, X.-Y. Yu, W.-J. Xiao, Synthesis, 2015, 604; (m) Y. Liu, R. Song, J. Li, Sci. China: Chem., 2016, 59, 161.

7. A. Wimmer, B. König, Beilstein J. Org. Chem., 2018, 14, 54.

8. E. L. Tyson, M. S. Ament, T. P. Yoon, J. Org. Chem., 2013, 78, 2046.

9. (a) E. L. Tyson, Z. L. Niemeyer, T. P. Yoon, J. Org. Chem., 2014, 79, 1427; (b) V. T. Bhat, P. A. Duspara, S. Seo, N. S. B. Abu Bakar, M. F. Greaney, Chem. Commun., 2015, 51, 4383; (c) C. A. DeForest, K. S. Anseth, Nat. Chem., 2011, 3, 925; (d) C. A. DeForest, K. S. Anseth, Angew. Chem., Int. Ed., 2012, 51, 1816; (e) H. Shih, C. C. Lin, Macromol. Rapid Commun., 2013, 34, 269; (f) H. Shih, A. K. Fraser, C. C. Lin, ACS Appl. Mater. Interfaces, 2013, 5, 1673; (g) D. Limnios, C. G. Kokotos, Adv. Synth. Catal., 2017, 359, 323; (h) O. O. Fadeyi, J. J. Mousseau, Y. Feng, C. Allais, P. Nuhant, M. Z. Chen, B. Pierce, R. Robinson, Org. Lett., 2015, 17, 5756-5759; (i) M. Singh, A. K. Yadav, L. D. S. Yadav, R. K. P. Singh, Tetrahedron Lett., 2017, 58, 2206-2208. (j) M. H. Keylor, J. E. Park, C.-J. Wallentin, C. R. J. Stephenson, Tetrahedron, 2014, 70, 4264.

10. (a) G. Zhao, S. Kaur, T. Wang, Org. Lett., 2017, 19, 3291; (b) S. Kaur, G. Zhao, E. Busch, T. Wang, Org. Biomol. Chem. 2019, 17, 1955.

11. H. Yorimitsu, K. Wakabayashi, H. Shinokubo, K. Oshima, Tetrahedron Lett. 1999, 40, 519.

12. Q. Wan, S. J. Danishefsky, Angew. Chem. Int. Ed. 2007, 46, 9249.

13. N. Floyd, B. Vijayakrishnan, J. R. Koeppe, B. G. Davis, Angew. Chem. Int. Ed. 2009, 48, 7798.

14. (a) D. Horton, J. D. Wander, Carbohydrates: Chemistry and Biochemistry, Vol. 4B, Academic Press, New York, 1990, p. 799 (b) R. T. Dere, X. Zhu, Org. Lett., 2008, 10, 4641; (c) G. J. L. Bernards, E. J. Grayson, S. Thompson, J. M. Chalker, J. C. Errey, F. El Oualid, T. D. W. Claridge, B. G. Davis, Angew. Chem., Int. Ed., 2008, 47, 2244; (d) G. J. L. Bernardes, D. P. Gamblin, B. G. Davis, Angew. Chem., Int. Ed., 2006, 45, 4007; (e) D. P. Gamblin, P. Garnier, S. van Kasteren, N. J. Oldham, A. J. Fairbanks, B. G. Davis, Angew. Chem., Int. Ed., 2004, 43, 827; (f) S. B. Cohen, R. L. Halcomb, J. Am. Chem. Soc., 2002, 124, 2534; (g) D. A. Thayer, H. N. Yu, M. C. Galan, C. H. Wong, Angew. Chem., Int. Ed., 2005, 44, 4596; (h) Y. Zhu, W. A. van der Donk, Org. Lett., 2001, 3, 1189; (i) Y. Zhu, M. D. Gieselman, H. Zhou, O. Averin, W. A. van der Donk, Org. Biomol. Chem., 2003, 1, 3304; (j) X. Zhu, K. Pachamuthu, R. R. Schmidt, J. Org. Chem., 2003, 68, 5641; (k) X. Zhu, R. R. Schmidt, Chem. Eur. J., 2004, 10, 875; (l) M. Fiore, A. Marra, A. J. Dondoni, Org. Chem., 2009, 74, 4422; (m) J. R. Rich, A. Szpacenko, M. M. Palcic, D. R. Bundle, Angew. Chem., Int. Ed., 2004, 43, 613; (n) H. Driguez, Top. Curr. Chem., 1997, 187, 85; (o) L. Szilagyi, O. Varela, Curr. Org. Chem., 2006, 10, 1745; (p) H. Driguez, ChemBioChem, 2001, 2, 311; (q) D. Crich, T. J. Ritchie, Carbohydr. Res., 1989, 190, 3; (r) J. P. Issa, D. Lloyd, E. Steliotes, C. S. Bennett, Org. Lett., 2013, 15, 4170; (s) P. Acharya, K. N. Baryal, C. Reno, J. Zhu, Carbohydr. Res., 2017, 448, 103; (t) K. N. Barayl, J. Zhu, Org. Lett., 2015, 17, 4530; (u) K. N. Barayl, D. Zhu, X. Li, J. Zhu, Angew. Chem., Int. Ed., 2013, 52, 8012. (v) P. L. Durette, T. Y. Shen, Carbohydr. Res. 1980, 81, 261. 
15. A. Talla, B. Driessen, N. J. W. Straathof, L. Milroy, L. Brunsveld, V. Hessel, T. Noel, Adv. Syn. Cat. 2015, 357, 2180.

16. (a) S. Fukuzumi, H. Kotani, K. Ohkubo, S. Ogo, N. V. Tkachenko, H. Lemmetyinen, J. Am. Chem. Soc., 2004, 126, 1600; (b) A. C. Benniston, K. J. Elliott, R. W. Harrington, W. Clegg, Eur. J. Org. Chem., 2009, 253; (c) A. Joshi-Pangu, F. Léveque, H. G. Roth, S. F. Oliver, L. Campeau, D. A. Nicewicz, D. A. DiRocco, J. Org. Chem., 2016, 81, 7244.

17. The proposed preference of oxidizing thiols over alkenes relies on their differences in reduction potentials. 